COMUNICAÇÃO CIENTÍFICA

\title{
COMPORTAMENTO DE HÍBRIDOS DE CITROS EM RELAÇÃO À INFECÇÃO NATURAL PELO Citrus tristeza virus E À PRESENÇA DE SINTOMAS DE DESCAMAMENTO ERUPTIVO'
}

\author{
ALMIR SANTOS RODRIGUES ${ }^{2}$, CRISTIANE DE JESUS BARBOSA ${ }^{3}$, \\ WALTER DOS SANTOS SOARES FILHO ${ }^{3}$, JULIANA FREITAS-ASTÚA ${ }^{3}$
}

RESUMO - O Programa de Melhoramento Genético de Citros da Embrapa Mandioca e Fruticultura vem gerando híbridos para utilização como porta-enxertos, que necessitam ser avaliados em relação ao comportamento frente à infecção natural por isolados locais de Citrus tristeza virus (CTV) e à presença de sintomas de descamamento eruptivo (Bahia Bark Scaling disease - BBS). Este trabalho apresenta resultados da avaliação do comportamento de 141 híbridos (sob a forma de pés-francos ou enxertados) estabelecidos na área experimental da Embrapa Mandioca e Fruticultura, no Recôncavo Sul da Bahia. Foram avaliadas a presença e a severidade de sintomas de caneluras e descamamento por meio de escala de notas. Para detectar a presença do CTV, foi utilizado o método sorológico de ELISA indireto e RT-PCR. Os híbridos avaliados foram classificados como imunes, tolerantes e intolerantes ao CTV. A maioria dos híbridos que apresentaram sintomas de BBS tem uma tangerineira como parental.

Termos para indexação: CTV, Citrus spp., Poncirus, Fortunella.

\section{BEHAVIOR OF CITRUS HYBRIDS IN RELATION TO NATURAL INFECTION BY THE Citrus tristeza virus AND THE PRESENCE OF SYMPTOMS OF BAHIA BARK SCALING DISEASE}

\begin{abstract}
The Citrus Breeding Program of Embrapa Cassava \& Fruits have been generating hybrids for using as rootstocks, which need to be evaluated in relation to behavior in the natural infection with local strains of Citrus tristeza virus, CTV and the presence of symptoms of flaking eruptive (Bahia Bark Scaling disease - BBS). This study presents the results of the evaluation of 141 hybrids (nucelar seedlings and grafted in rootstocks) stated in the experimental area of Embrapa Cassava \& Fruits in the Southern Recôncavo of the states of Bahia. Severity of stem pitting of CTV and BBS symptoms were evaluated by using a rating scale. It was used serological method of ELISA (indirect method) to detect the presence of CTV and RT-PCR. The hybrids evaluated were classified as immunes, tolerant and intolerant to CTV. Most of the hybrids that showed symptoms of BBS had a mandarin as parental.
\end{abstract}

Index terms: CTV, Citrus spp., Poncirus, Fortunella.

${ }^{1}$ (Trabalho 179-13). Recebido em: 14-05-2013. Aceito para publicação em: 26-06-2014.

${ }^{2}$ Eng. Agr., Universidade Federal do Recôncavo da Bahia - UFRB, Câmpus Universitário de Cruz de Almas, Bahia, s/n. Email: almirsomalia@yahoo.com.br

${ }_{3}^{3}$ Pesquisador(a) da Embrapa Mandioca e Fruticultura, 44380-000, Cruz das Almas, Bahia, Caixa Postal 007. Email: cristiane.barbosa@embrapa.br; walter.soares@embrapa.br; juliana.astua@embrapa.br 
O Brasil é o segundo maior produtor de citros do mundo (FAO, 2014), esta cultura, no entanto, está sujeita a doenças importantes, como a tristeza, causada pelo vírus-da- tristeza-dos-citros (Citrus tristeza virus - CTV), que infecta praticamente todas as espécies, cultivares e híbridos de citros. O CTV é um vírus do gênero Closterovirus, transmitido pelo pulgão-preto-dos-citros, Toxoptera citricidus Kirkaldy, e por material propagativo infectado (MORENO et al., 2008; SOLER et al., 2012). Ocorre na forma de diversos isolados, frequentemente coinfectando uma mesma planta. A sintomatologia depende das condições do ambiente, da idade e da capacidade da planta em permitir a multiplicação do vírus e a tolerância dos tecidos, podendo manifestarse como amarelecimento das mudas, declínio rápido, declínio moderado e caneluras (MÜLLER et al., 2005; MORENO et al., 2008).

No Brasil, o vírus e o vetor são endêmicos e para o controle têm-se utilizado porta-enxertos tolerantes ao CTV e a pré-imunização. A tolerância à tristeza é, então, pré-requisito necessário à obtenção de novas variedades porta-enxerto (MÜLLER et al., 2005). Segundo Bordignon et al. (2003), intensos esforços têm sido despendidos no estudo da resistência ou imunidade ao CTV, que se caracteriza pela incapacidade de multiplicação do vírus na planta, e já foram identificados três genes independentes, conferindo essa imunidade: Ctv1 (CRISTOFANI et al., 1999) presente em Poncirus trifoliata (L.) Raf.; Ctv2 (FANG; ROOSE, 1999) encontrado em Citrus maxima (Burm.) Merr. e Ctm (MESTRE et al., 1997).

O descamamento eruptivo dos citros (Bahia Bark Scaling disease - BBS) é uma doença restrita à citricultura da Bahia e Sergipe, e de etiologia ainda desconhecida (ALIOTO et al., 1999; MARTIN et al., 2006). Os sintomas caracterizamse pelo descamamento no tronco e ramos mais antigos e, muitas vezes, exsudação de goma. Afeta principalmente os pomeleiros (C. paradisi), as tangerineiras $(C$. reticulata) e também as laranjeirasdoces (C. sinensis). Em plantios mais velhos de laranjeira-doce, a incidência da doença pode ser superior a 80\% (BARBOSA et al., 1999; NICKEL et al., 2007).

O objetivo deste trabalho foi avaliar a reação de híbridos gerados pelo Programa de Melhoramento Genético de Citros da Embrapa Mandioca e Fruticultura (PMG Citros) à infecção natural por isolados locais do CTV e à presença de sintomas de descamamento eruptivo.

O trabalho foi conduzido no campo experimental da Embrapa Mandioca e Fruticultura, localizado no município de Cruz das Almas, Bahia. Híbridos selecionados foram avaliados em duas condições: 49 indivíduos estabelecidos como copas enxertadas em limoeiro 'Volkameriano' (C. volkameriana V. Ten. \& Pasq.) e 92 híbridos estabelecidos como pés-francos (seedlings).

Os híbridos estabelecidos como copas enxertadas em limoeiro 'Volkameriano' apresentavam nove anos de idade e foram obtidos dos seguintes parentais: híbrido trifoliado (HTR), limoeiro 'Volkameriano'(LVK), limoeiro 'Cravo' (C. limonia Osbeck) (LCR), laranjeira-doce 'Palmeiras' (LPA), laranjeira-doce 'Valência' (LVA), limoeiro 'Rugoso (C. jambhiri Lush.) da Flórida’ (LRF), citrange 'Yuma' (CTYM), tangerineira 'Sunki' [C. sunki (Hayata) hort. ex Tanaka] (TSK), P. trifoliata (TR). Os híbridos estabelecidos como pés-francos, com idade entre nove e 17 anos, foram obtidos dos seguintes parentais: tangerineiras 'Sunki' comum (TSKC), 'Sunki da Flórida' (TSKFL), 'Clementina' (C. clementina hort. ex Tanaka) comum (TCLC) e 'Clementina de Nules' (TCLN), mexeriqueira $(C$. deliciosa Ten.) 'Willow Leaf' (MXWL), híbrido trifoliado, P. trifoliata (TR), P. trifoliata seleções 'Beneke' (TRBK), Diploide (TRDP) e 'Flying Dragon' (TRFD), citranges 'Troyer' (CTTR), 'Argentina' (CTARG), 'C13' (CTC13) e 'Coleman' (CTCM), citrumelo 'Swingle' (CTSW), citrangequat (Fortunella Swingle x citrange) 'Thomasville' 1439 (CTQT1439), limoeiros 'Cravo', 'Cravo' comum (LCRC), 'Cravo Estação Experimental de Limeira' (LCREEL), 'Rugoso da Flórida' (LRF), 'Rugoso Mazoe' (LRM) e 'Volkameriano Catânia 2' (LVKCT2), laranjeiras-doces 'Hamlin' (LHA) e 'Pera CNPMFD6' (LPED6) e C. webberi Wester (CWEB).

A avaliação para a presença e a severidade de caneluras foi realizada por meio da leitura de dez ramos com cerca de $20 \mathrm{~cm}$, coletados nos diferentes quadrantes de cada planta híbrida estudada, usandose a escala de notas descrita por Meissner Filho et al. (2002), que variou de 1 - ausência de caneluras, a 5 - toda a superfície do ramo coberta por caneluras.

A presença e a concentração do CTV nas plantas foram determinadas por ELISA indireto (Indirect Enzyme-Linked Immunoabsorbent Assay (KOENIG, 1981). Para tanto, foram utilizadas amostras de casca de ramos novos, que foram macerados em tampão carbonato $\left(\mathrm{Na}_{2} \mathrm{CO}_{3} 0,015\right.$ $\mathrm{M} ; \mathrm{NaHCO}_{3}$ 0,035 M) e diluídas em 1:100 (p/V) em três repetições, o antissoro policlonal para CTV diluído a 1:1.000 em tampão para diluição do antissoro [PBS-Tween 0,05\% ( $\mathrm{NaCl} 0,14 \mathrm{M}$; $\mathrm{KH}_{2} \mathrm{PO}_{4}$ 0,0014 M; $\mathrm{Na}_{2} \mathrm{HPO}_{4} 0,008 \mathrm{M} ; \mathrm{KCl} 0,0027$ 
M) $+2 \%$ de PVP $+0,2 \%$ de albumina de ovo] e o anti-rabbit $\mathrm{IgG}$ - fosfatase alcalina também diluído a 1:1.000 em tampão para diluição do antissoro. Como controle negativo, utilizou-se de amostras de P. trifoliata, e como positivo, de limoeiro 'Galego' (C. aurantiifolia). As leituras de absorbância foram realizadas na leitora de placas de ELISA (ELx 800 Universal Microplate Reader), após dez minutos de reação com o tampão substrato $\left(0,87 \mathrm{mg} \mathrm{L}^{-1}\right.$ de $\mathrm{p}$-nitrofenil fosfato). Para determinar o valor de absorbância-limite que permitiu diagnosticar amostras infectadas e sadias, utilizou-se da média do controle negativo, acrescido de três vezes o desviopadrão calculado $(\mathrm{x}+3 \mathrm{~s})$.

Para a extração de RNA total, utilizouse do produto comercial Trizol (Invitrogen), seguindo-se as recomendações do fabricante. O RNA extraído foi quantificado por fluorometria ("Qubit'TM Fluorometer"; kit "Quant-iT"M RNA assay kit”, Invitrogen). Após a quantificação, foi feita a transcrição reversa (RT) das amostras de RNA total, seguida de amplificação por PCR com os primers específicos P23 e P20 (RUBIO et al., 2001), tendo como controle positivo amostras de laranjeira 'Pera IAC' e como negativo, amostras de plantas microenxertadas. Para a RT, foi utilizada a enzima transcriptase reversa "SuperScript ${ }^{\mathrm{TM}}$ II Reverse Transcriptase" (Invitrogen), e para a amplificação, a "Taq DNA Polymerase" (Invitrogen). Foi utilizado para a reação total $1,8 \mu \mathrm{g}$ de RNA total, tratado com DNAs e, juntamente com primers específicos para os genes em estudo. O cDNA gerado a partir desta reação, em um volume de $1 \mu \mathrm{L}$ da reação de transcrição reversa contendo $0,08 \mu \mathrm{g}$ de RNA total, foi então submetido a reação de PCR, e seu produto, separado por eletroforese em gel de agarose ( $1 \%$ ) corado com brometo de etídeo, visualizado e fotografado em transiluminadores UV.

Baseando-se na escala de notas utilizada na avaliação para caneluras de CTV, nos resultados obtidos no teste de ELISA indireto e na análise de RT-PCR, foi definida uma classificação dos híbridos, conforme descrito a seguir (BORDIGNON et al., 2003): (R) Resistente - ausência de caneluras e de vírus em seus tecidos; (T) Tolerante - presença de caneluras esparsas; (I) Intolerante - número intermediário de caneluras - toda a superfície do ramo coberta por caneluras.

A avaliação para a presença e a intensidade de descamamento foi realizada por meio de uma escala de notas descrita por Barbosa et al. (1999), que variou de 0 - ausência de lesões a 3 - presença de grandes lesões em todo o tronco principal e na maioria dos ramos.
Os resultados da avaliação de sintomas de caneluras nos híbridos mostraram que a maioria é tolerante às estirpes locais de CTV (Tabela 1). Os híbridos que apresentaram maiores notas para a presença e a severidade de caneluras foram: LVK x LPA - 002, LVK x LVA - 009 e LVK x LCR - 059. Alguns híbridos HTRs, que têm o $P$. trifoliata como parental, imune ao CTV (POMPEU JUNIOR;BLUMER, 2009), também apresentaram caneluras acentuadas de tristeza. A avaliação sorológica indicou que alguns híbridos com maior severidade de caneluras, como LVK x LCR - 059, LVK x LPA - 002 e LVK x LVA - 009, apresentaram também maiores leituras de absorbância na reação sorológica contra o CTV, confirmando assim maior suscetibilidade e intolerância ao vírus. Esta avaliação também identificou híbridos, como HTR - 002, HTR - 015, HTR - 073, HTR - 127 e HTR - 135, que, mesmo apresentando poucas caneluras (Tabela 1), mostraram-se positivos para a presença de CTV no teste sorológico, podendo os mesmos serem considerados tolerantes ao vírus. Por outro lado, somente alguns dos híbridos trifoliados (HTRs) não foram positivos para a detecção do CTV em seus tecidos pelo método sorológico adotado. De modo geral, também foram os híbridos HTRs que mostraram as menores leituras de absorbância na reação sorológica contra o $\mathrm{CTV}$, principalmente se comparados com os híbridos oriundos de cruzamentos com laranjeiras-doces, suscetíveis ao vírus. Apesar de os HTRs possuírem genes de $P$. trifoliata (SOARES FILHO et al., 2008), imune ao vírus da tristeza, a ocorrência de híbridos sensíveis também é possível, já que os híbridos de $P$. trifoliata podem ser tolerantes ou não à tristeza (FORNER ;FORNER-GINER, 2002).

A maioria dos híbridos estabelecidos como copas $(56,6 \%)$ foi tolerante ao vírus da tristeza; somente $1,88 \%$ dos híbridos foi imune ao CTV. Do mesmo modo, a maioria dos híbridos estabelecidos como pés-francos mostrou-se tolerante à tristeza. Provavelmente, este resultado seja determinado pelo fato de a maior parte dos cruzamentos utilizados ter envolvido o $P$. trifoliata, citranges, tangerineiras, limoeiros 'Cravo', 'Rugoso' e 'Volkameriano', que são considerados tolerantes ou imunes ao CTV (SANTOS et al., 2007; POMPEU JUNIOR;BLUMER, 2009). Por outro lado, os híbridos obtidos do cruzamento com $C$. webberi, intolerante ao CTV, apresentaram os sintomas mais evidentes de caneluras de tristeza (Tabela 1).

A avaliação sorológica para presença de CTV nos tecidos dos híbridos sob a forma de seedlings mostrou que alguns indivíduos com maior número de 
caneluras, como TSKC x CTQT1439 - 003, TSKC x CTARG - 079 e TSKFL x CWEB - 004, apresentaram leituras altas de absorbância na reação sorológica contra o CTV, confirmando assim a suscetibilidade ao vírus. As amostras consideradas negativas pelo ELISA indireto também foram analisadas por RTPCR e somente as amostras de HTR - 206, TCLN x TRDP - 015 e LCRC x LRF - 034 se mostraram infectadas.

A partir desses resultados, foi possível diagnosticar que $14,95 \%$ dos híbridos estabelecidos como pés-francos se mostraram resistentes, $53,75 \%$ tolerantes e 15,04\% intolerantes ao CTV Alguns híbridos, como TSKC x CTSW - 047, TSKC x TRFD - 006, TSKC x TRDP - 023, TSKC x CTQT1434 - 001 e TSKC x LHA - 006, embora tenham apresentado algumas caneluras em seus ramos, não estavam infectados pelo CTV.

A maioria, 55\% dos híbridos, apresentou descamamento e exsudação de goma no tronco principal e nos ramos. Do total de híbridos avaliados, $23 \%$ mostraram sintomas de descamamento quando estabelecidos como copas e $76 \%$ quando estabelecidos como pés-francos. Os híbridos TSKC x CTARG 019, TSKC x CTQT $1439-036$, TSKC $\mathrm{x}$ (LCR $\mathrm{x}$ TR) 001, TSKC $\mathrm{x}$ (TR $\mathrm{x}$ LCR) 073, TSKC x CTARG 001, TSKC x CTARG 020, TSKC x CTARG 043, TSKC x CTARG 079, TSKC x CTQT 1434 - 010, TSKC x CTQT 1439 - 014, TSKC x CTQT $1439-026$, TSKC x CTSW 028, TSKC x CTSW 031, TSKC x CTSW 033, TSKC x CTSW 038, TSKC x CTTR 012, TSKC x CTTR 017 e TSKC x CTTR 028, cujo um dos parentais foi a tangerineira 'Sunki' comum (TSKC), sensível ao BBS (BARBOSA et al., 1999; NICKEL et al., 2007), foram os que apresentaram sintomas mais agressivos. Esses híbridos, em sua maioria, apresentaram descamamento em, pelo menos, $33 \%$ das plantas avaliadas dentro de cada cruzamento com TSKC, mostrando-se suscetíveis, seja quando estabelecidos como copas, seja como pés-francos.

A avaliação para a tolerância a essas doenças é um importante objetivo a ser considerado num programa de melhoramento genético de portaenxertos de citros, principalmente se as mesmas forem endêmicas, a exemplo da tristeza no Brasil. 


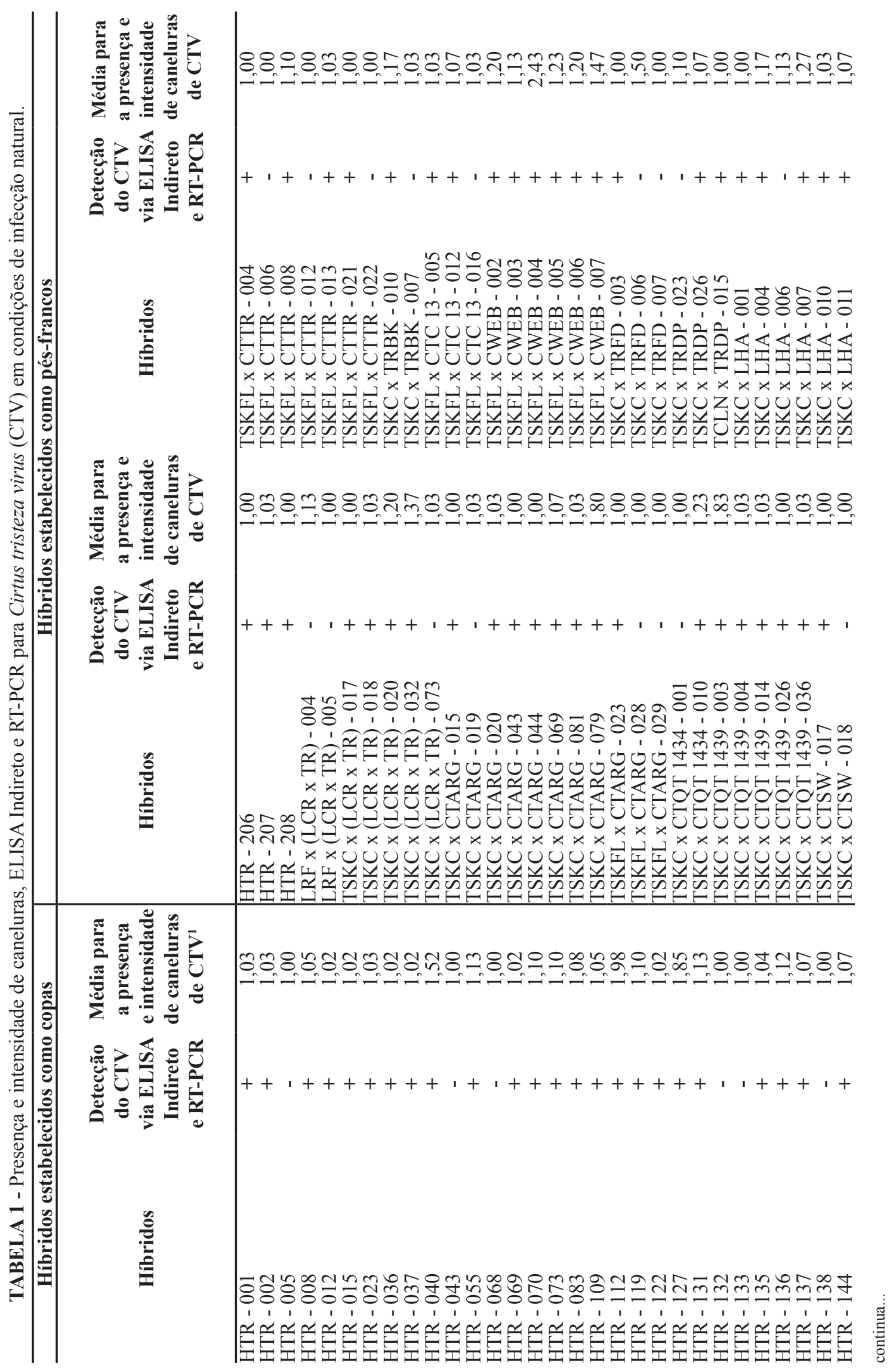




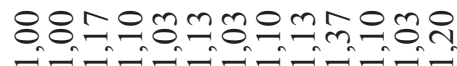

$+++++++1+++$

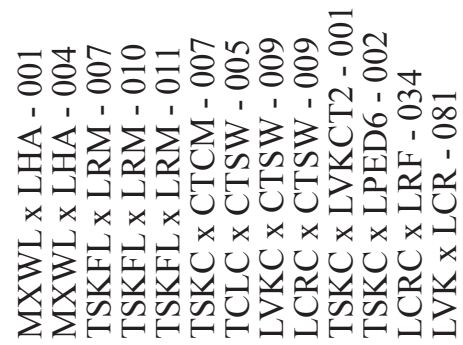

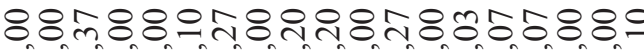
$1,1+1++1,1+++1,1,1+11$

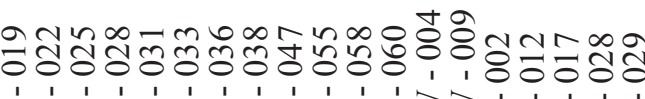

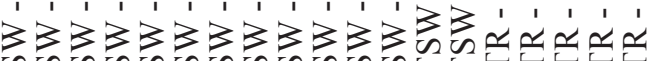

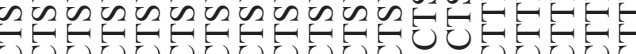
๖

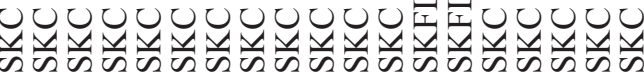

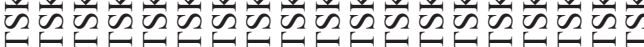

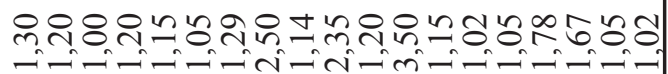
$+++++1++++++1++1+$

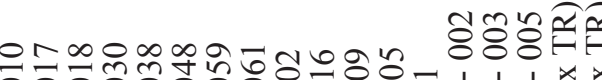
$\begin{array}{lllll}1 & 1 & 1 & 1 & 1\end{array}$

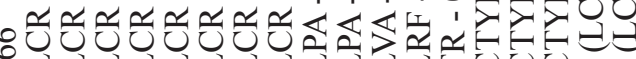

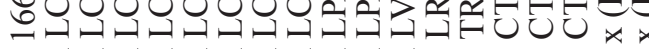

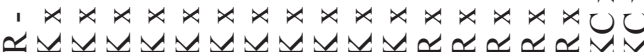

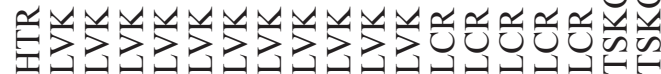

\section{CONCLUSÕES}

Foi possível identificar oitenta híbridos como tolerantes, dezessete híbridos como provavelmente resistentes (imunes) e vinte e quatro híbridos intolerantes aos isolados locais de CTV. A maioria dos híbridos avaliados apresentou sintomas de descamamento eruptivo.

\section{REFERÊNCIAS}

AliOTO, D.; GANGEMI, M.; DEAGLIO, S.; SPOSATO, S.; NORIS, E.; LUISONI, E.; MILNE, R.G. Improved detection of citrus psorosis virus using polyclonal and monoclonal antibodies. Plant Pathology, Oxford, v.48, 735-741, 1999.

BARBOSA, C.J.; VALVERDE, P.R.H.; ALMEIDA, R.S.; SANTOS FILHO, H.P.; NICKEL, O.; VILARINHOS, A.D. Incidência e severidade de sintomas de sorose tipo Bahia em variedades de laranjas-doces. Revista Brasileira de Fruticultura, Jaboticabal, v.21, n.3, p.382-384, 1999.

BORDIGNON, R.; MEDINA FILHO, H.P.; MULLER, G.W.; SIQUEIRA, W.J. A tristeza dos citros e suas implicações no melhoramento genético de porta-enxertos. Bragantia, Campinas, v.62, n.3, p.345-355, 2003.

CRISTOFANI, M.; MACHADO, M. A.; GRATTAPAGLIA, D. Genetic linkage maps of Citrus sunki Hort. ex. Tan. and Poncirus trifoliata (L.) Raf. and mapping of Citrus tristeza virus resistance gene. Euphytica, Dordrecht, v.109, p.2532, 1999.

FANG, D.Q.; ROOSE, M.L. A novel gene conferring Citrus tristeza virus resistance in Citrus maxima (Burm.) Merrill. HortScience, Alexandria, v.34, n.2, p.334-335, 1999.

FAO. FAOSTAT. Database result. Disponível em: $<$ http://faostat.fao.org > . Acesso em: abr. 2014.

FORNER, J.B.; FORNER-GINER, M.A. Programa de melhoramento de porta-enxertos cítricos na Espanha. In: DONADIO, L.C.; STUCHI, E.S. (Ed.). In: SEMINÁRIO INTERNACIONAL DE CITROS, 7., Bebedouro: EECB, 2002. p.82-95.

KOENIG, R. Indirect ELISA methods for the broad specificity detection of plant viruses. Journal of General Virology, London, v.55, p.53-62, 1981. 
MARTIN, S.; GARCIA, M.L.; TROISIS, A.; RUBIO, L.; LEGARRETI, G.; GRAU, O.; ALIOTO, D.; MORENO, P.; GUERRI, J. Genetic variation of populations of Citrus psorosis virus. Journal of General Virology, London, v.87, p.3097-3102, 2006.

MEISSNER FILHO, P.E.; SOARES FILHO, W.S.; VELAME, K.V.C.; DIAMANTINO, E.P. Reação de porta-enxertos híbridos ao Citrus tristeza virus. Fitopatologia Brasileira, Brasília, v.27, n.3, p.312$315,2002$.

MESTRE, P.F.; ASINS, M.I.; CARBONELL, E.A.; NAVARRO, L. New gene(s) involved in the resistance of Poncirus trifoliata (L.) Raf. to Citrus tristeza virus. Theoretical and Applied Genetics, New York, v.95, p.691-695, 1997.

MORENO, P.; AMBRÓS, S.; ALBIACH-MARTI, M.R.; GUERRI, J.; PEÑA, L. Citrus tristeza virus: a pathogen that changed the course of the citrus industry. Molecular Plant Pathology, London, v.9, n.2, p.251-268, 2008.

MÜLLER, G.W.; TARGON, M.L.P.N.; CARVALHO, A.S.; SOUZA, A.A.; RODRIGUES, J.C.V. Doenças de citros causadas por vírus e viroides. In: MATTOS JÚNIOR, D.; DENEGRI, J.D.; PIO, R.M.; POMPEU JÚNIOR, J. (Ed.). Citros. Campinas: Instituto Agronômico e Fundag, 2005. p.569-604.

NICKEL, O.; BARBOSA, C.J.; SANTOS FILHO, H.P.; PASSOS, O.S.; LARANJEIRA, F.F. Bahia bark scaling of citrus: a disease of unknown etiology. Pest Technology, Kagawa, v.1, p.70-75, 2007.
POMPEU JUNIOR, J.; BLUMER, S. Híbridos de trifoliata como porta-enxertos para a laranjeira 'Valência'. Pesquisa Agropecuária Brasileira, Brasília, v.44, n.7, p.701-705, 2009.

RUBIO, L.; AYLLÓN, M.A.; KONG, P.; FERNÁNDEZ, A.; POLEK, M.I.; GUERRI, J.; MORENO, P.; FALK, B.W. Genetic variation of Citrus tristeza virus (CTV) isolates from California and Spain: evidence for mixed infections and recombination. Journal of Virology, Washington, v.75, p.8054-8062, 2001.

SANTOS, F.A.; CARVALHO, S.A.; SOUZA, A.A.; MACHADO, M.A. Estabilidade do complexo Pera IAC do Citrus tristeza virus em quatro cultivares de laranja-doce. Laranja, Cordeirópolis, v.28, n.1-2, p.17-28, 2007.

SOARES FILHO, W.S.; LEDO, C.A.S.; PASSOS, O.S.; SOUZA, A.S.; MATTOS, L.A.; QUINTELA, M.P. Parentais femininos monoembriônicos na obtenção de porta-enxertos híbridos de citros. Revista Brasileira de Fruticultura, Jaboticabal, v.30, n.1, p.215-218, 2008.

SOLER, N.; PLOMER, M.; FAGOAGA, C.; MORENO, P.; NAVARRO, L.; FLORES, F.; PEÑA, L. Transformation of Mexican lime with an intronhairpin construct expressing untranslatable versions of the genes coding for the three silencing suppressors of Citrus tristeza virus confers complete resistance to the virus. Plant Biotechnology Journal, Oxford, v.10, p.1-12, 2012. 